\title{
Air Purification Capability of Potted Phoenix Roebelenii and Its Installation Effect in Indoor Space
}

\author{
Kang Baosheng*, Shin-ichi Shibata, Ayako Sawada, \\ Takashi Oyabu and Haruhiko Kimura ${ }^{1}$ \\ Kanazawa Seiryo University, 10 Ushi, Gosho-machi, Kanazawa City, Ishikawa 920-8620, Japan \\ ${ }^{1}$ Faculty of Engineering, Kanazawa University, 2-40-20 Kodatsuno, \\ Kanazawa City, Ishikawa 920-8667, Japan
}

(Received January 21, 2009; accepted June 26, 2009)

Key words: potted plant, Phoenix roebelenii, air purification, healing effect, work environment

Phoenix roebelenii (commonly called Roebelenii palm or dwarf date palm) is a wellknown potted plant, which is endemic to Hachijyo Island in Japan. It is commonly called "Roebe." Roebe production is an important industry on the island. Most products of this industry are exported to Europe. The export volume has been decreasing since 2001 and the producers of Roebe are badly affected by this decrease. The reason for the decrease is that cheap Roebes from South America are now exported to Europe. Roebe is placed in indoor spaces, namely, offices and homes, because it has a healing effect and an air-purifying function. It is necessary to revitalize the agricultural industry in Hachijyo by characterizing the positive features of the Hachijyo Roebe. In this study, the air purification capability $\left(P_{\mathrm{a}}\right)$ considering environmental factors (temperature and light intensity) and the healing effect of Roebe were examined with the goal of increasing the export volume of this plant. Results showed that $P_{\mathrm{a}}$ increased with an increase in room temperature from 21 to $26^{\circ} \mathrm{C}$, reaching a range of $15-35$. It became clear that Roebe has a substantial purification function. It also became clear that it has a healing effect to some degree. The effect was evaluated using an instrument that measures the amylase activity in the saliva of subjects. The relationship between $P_{\mathrm{a}}$ and the molecular weight of a polluting chemical was also examined. Results showed that $P_{\text {a }}$ decreased as the weight increased.

\section{Introduction}

Several hundred millions of years have elapsed since terrestrial plants emerged. Humans have been living with plants throughout their history and plants have made various contributions to human life. Humans desire emotional recovery and take great comfort from the presence of plants. ${ }^{(1)}$ Plants degrade air pollutants and greenhouse

${ }^{*}$ Corresponding author: e-mail: kohousyou1208@yahoo.co.jp 
gases discharged by humans.(2) Therefore, plants have been placed in indoor spaces, such as in living and working environments. It has been clarified that workplace productivity increases with the presence of potted plants. ${ }^{(3)}$ Work and living spaces can be improved by taking advantage of plant functions (contribution degree). Humans can easily place plants in most types of working environments. Humans spend much time in enclosed environments including those in ships, cars, and airplanes. Plants are even needed for humans to live in space shuttles. ${ }^{(4)}$ Gaseous air pollutants are generated in a superinsulated space. These pollutants are emitted by humans and building materials. Plants can absorb these gases and emit oxygen when there is sufficient light intensity. The concentration of carbon dioxide in the presence of plants does not reach excessive levels even in darkness. ${ }^{(5-6)}$

Phoenix roebelenii (popularly known as "Roebe") is grown on Hachijyo Island in Japan. The market share of producers on the island exceeds $97 \%$ in Japan. It is exported to the EU as well as to other prefectures in Japan. It is placed indoors. On Hachijyo Island, the agricultural production of Roebe is the key industry. The industry on the island has recently been hit by the increasing production of this plant in Guatemala and Costa Rica. These countries also export Roebe to the EU. A potted Roebe produced on Hachijyo costs about 10,000 to 20,000 Yen, but those produced in the above countries cost about 3,500 Yen. However, the Japanese type is superior in terms of brightness of leaf reflection and leaf shape: the leaves are slender. In this study, the air purification capability of the Hachijyo Roebe was examined to identify any distinctive positive characteistics. It is thought that the industry can recover its once increasing export volume of Roebe. For this reason, the capability of Roebe to absorb formaldehyde (HCHO) was investigated as a function of temperature and light intensity. This chemical is the main causative substance of sick house syndrome. The results show clearly that Roebe has a relatively high absorption capability in addition to exhibiting a healing effect to some extent. It is thought that Roebe is effective indoors.

\section{Experimental Procedure}

\subsection{Air purification capability}

The air purification capability of Roebe was evaluated in an enclosed chamber made of acrylic. The chamber is $575 \mathrm{~mm}$ long, $510 \mathrm{~mm}$ wide, and 1,000 $\mathrm{mm}$ high, and has a capacity of about $300 \mathrm{~L}$. A potted Roebe was placed in the chamber and each test chemical was injected into the chamber using a microsyringe. The chemicals were formaldehyde, toluene, xylene, and styrene, which cause sick house syndrome. The concentration of each injected chemical decreased owing to the purification function of Roebe. The concentration was measured using a gas sensor (TGS \#826; Figaro Co., Osaka). The sensor is a type of alarm detector. The resistance of the sensor decreases when a reducing gas (the above-mentioned chemicals) is present in the atmosphere. The resistance is also affected by atmospheric temperature, humidity, and pressure to some degree. Temperature markedly affects the resistance. Therefore, the temperature in the experimental room was controlled using an air-conditioner. The humidity in the room was also kept low. The purification capability was evaluated using the sensor output. 
The basic measurement circuit of the output is indicated in Fig. 1. The sensor resistance $R_{\mathrm{s}}$ and the load resistance $R_{\text {out }}$ were connected in series and the dc voltage $V_{\mathrm{c}}$ was applied to the circuit. $R_{\mathrm{s}}$ decreases when the concentration of a reducing gas increases, and the output $V_{\text {out }}$ at both ends of $R_{\text {out }}$ increases. The output is determined using eq. (1).

The sensor output $V_{\text {out }}$ was converted into a digital signal through an A-D converter and the signal was inputted into a data logger. Subsequently, the signal was inputted into a mobile computer. The sampling interval was $1 \mathrm{~min}$. Sunlight was blocked and daylight fluorescent lamps were used in the experimental room at one stage. Sunlight through paned windows was adopted at another stage. Light intensity was controlled using the above-mentioned lights. Atmospheric temperature was controlled using an air conditioner, but the temperature control accuracy was not good. The Roebe was watered one day before the measurement using $100 \mathrm{cc}$ of water. Photographs of the Roebe and the experimental chamber in which the Roebe was placed are shown in Fig. 2. The height of the Roebe was $93 \mathrm{~cm}$ from the pot bottom. The pot was $20 \mathrm{~cm}$ in diameter and $26 \mathrm{~cm}$ in height. The soil in the pot was a planter mix.

The typical purification characteristic is shown in Fig. 3. The base level (offset level) was measured for $1 \mathrm{~h}$ and a chemical was injected into the chamber, as shown in the figure. After the chemical was injected, sensor output $\left(V_{\text {out }}\right)$ increased rapidly with the chemical concentration, namely, the sensor resistance decreased when the chemical was injected. The sensor output returned to its base level as a result of the purification capability of the Roebe. The capability $\left(P_{\mathrm{a}}\right)$ is derived using a maximum $V_{\text {out }}$ (symbol $\mathrm{h}$ is adopted in the figure) from the base level and the half-value width $t_{\mathrm{w}} . P_{\mathrm{a}}$ is defined in eq. (2). It becomes large when the rate of decrease is larger than the pollutant concentration. The capability can be compared with other plant purification capabilities.

$$
\begin{gathered}
V_{\text {out }}=V_{\mathrm{c}} \times R_{\text {out }} /\left(R_{\mathrm{s}}+R_{\text {out }}\right) \\
P_{\mathrm{a}}=h / t_{\mathrm{w}} \times 100
\end{gathered}
$$

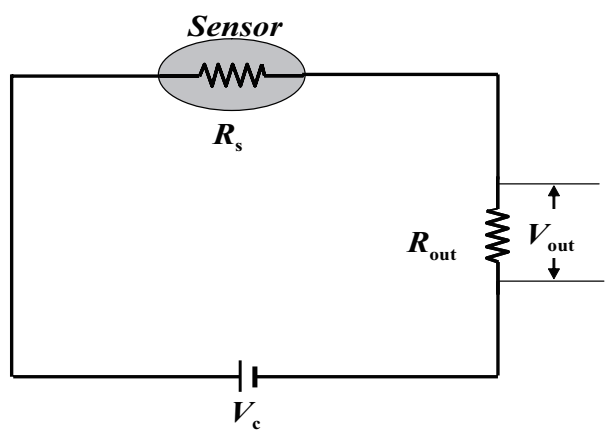

Fig. 1. Basic measuring circuit for sensor output. 


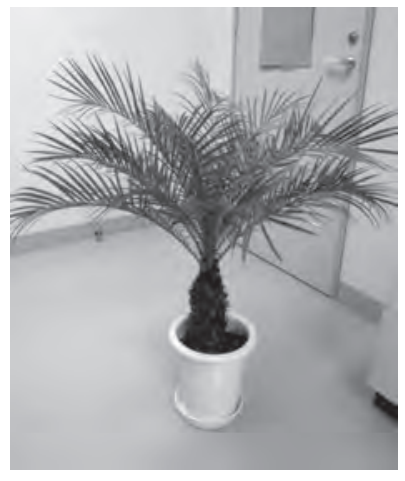

(a)

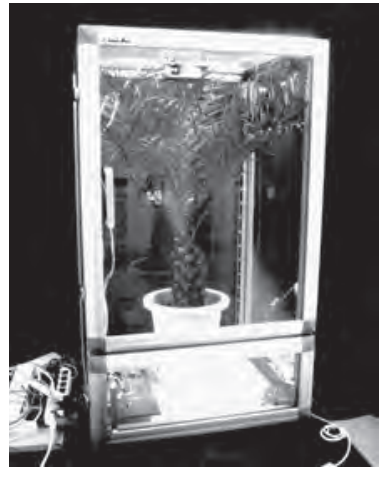

(b)

Fig. 2. Photographs of Phoenix roebelenii and experimental system. (a) Phoenix roebelenii. (b) Experimental chamber in which Roebe is installed.

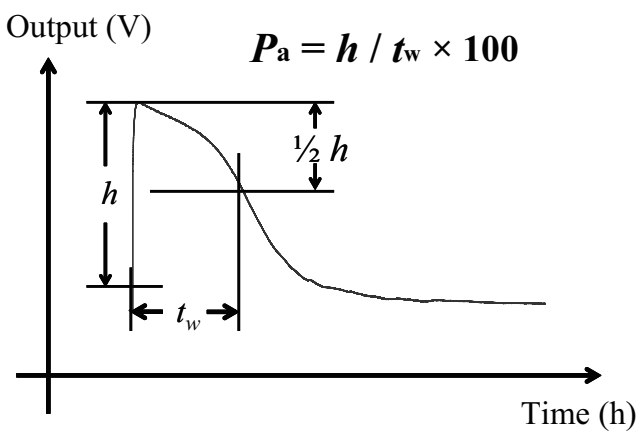

Fig. 3. Evaluation method of air purification capability of Roebe.

\subsection{Stress-relieving capability}

Stress has become an increasingly important issue because of changing working environments and lifestyles. Humans easily get sick with stress. Fatigue sometimes causes stress. Selye used the term "stress" in connection with a living organism for the first time in 1953. Rest and healing are necessary to avoid the accumulation of stress. ${ }^{(7)}$ Healing is very difficult to define and there is as yet no appropriate definition. There are various types of approaches to reduce stress, for instance, music, travel, and aroma. It is often said that forest therapy and horticulture also have a marked effect. ${ }^{(8)}$ Humans have had a close relationship with plants over a long period of time and have experienced emotional recovery by living with plants. 
The amylase activity of humans increases with the excitation of the sympathetic system by a stress from outside the body as part of a self-defense reaction. ${ }^{(9)}$ It can be determined whether or not humans are stressed by measuring amylase activity. Equipment for analyzing saliva amylase activity (Nipro Co., COCORO Meter) was used, and the healing effect of Roebe was measured.(7) The activity is measured using a measuring sheet that can sample the saliva of a subject. Namely, the sheet is placed in the mouth and then saliva is analyzed using the equipment. It takes about $1 \mathrm{~min}$ to measure and analyze the saliva sample.

The measurement steps are as follows. Each step was carried out in the presence and absence of Roebe. The data were compared and the healing effect of Roebe was determined. The suffix $n$ denotes the absence of Roebe. The suffix $r$ denotes the presence of Roebe, for example, $h_{\mathrm{bn}}$ and $h_{\mathrm{br}}$. The difference between the factors is dealt with as a mitigation grade (healing grade). Base levels $\left(h_{\mathrm{bn}}\right.$ and $\left.h_{\mathrm{br}}\right)$ are compared with levels after stress by the following procedure.

1. Measure amylase activity $h_{\mathrm{b}}$ (base level)

2. Input text into a word processor for $10 \mathrm{~min}$

3. Measure amylase activity $\left(h_{\mathrm{s}}\right)$ again (measurement of stress)

4. Measure amylase activity $\left(h_{\mathrm{r}}\right) 30 \mathrm{~min}$ later (stress relieved)

\section{Experimental Results}

\subsection{Purification capability of Roebe for formaldehyde}

Formaldehyde is one of the main causative substances of sick house syndrome. Its concentration indoors is restricted to $0.08 \mathrm{ppm}\left(100 \mu \mathrm{g} / \mathrm{m}^{3}\right.$ at $\left.25^{\circ} \mathrm{C}\right)$ by the Ministry of Health, Labor and Welfare of Japan. The value is a guideline. There are twelve additional restricted substances. Formaldehyde was injected into the chamber at a concentration 100-fold that of the guideline $(8 \mathrm{ppm})$ in this experiment and the purification capability was examined. Plants absorb substances through their stomata under ordinary circumstances. However, the stalk of Roebe is porous and can absorb some pollutants. Namely, its capability may be slightly high. Equation (2) is, however, adopted to evaluate the purification capability of Roebe under normal conditions. The purification characteristic of Roebe for formaldehyde at $8 \mathrm{ppm}$ is indicated in Fig. 4. The vertical axis denotes the concentration change and the horizontal axis denotes the elapsed time. The characteristic was measured at room temperature $\left(26^{\circ} \mathrm{C}\right)$ and a light intensity of 1,000 lx. The characteristic increased rapidly after the injection of formaldehyde and decreased according to Roebe's purification function. The level returned to the base level. In the figure, $h$ is $0.36[\mathrm{~V}], t_{\mathrm{w}}$ is $1.05[\mathrm{~h}]$, and $P_{\mathrm{a}}$ is 34 . The $P_{\mathrm{a}}$ of Roebe is relatively high compared with those of other plants. As an example, pothos (Epipremnum aurum) has a higher purification capability. The $P_{\mathrm{a}}$ of pothos is shown in Fig. 5. The experimental conditions are similar to those in Fig. 4. It is thought that indoor air quality has been considerably improved in Europe owing to Roebe. Note that Europe is the main destination of exported Roebe. The purification capability changes with light intensity and atmospheric temperature. It becomes higher when the room temperature is in the range of the growing temperature. 


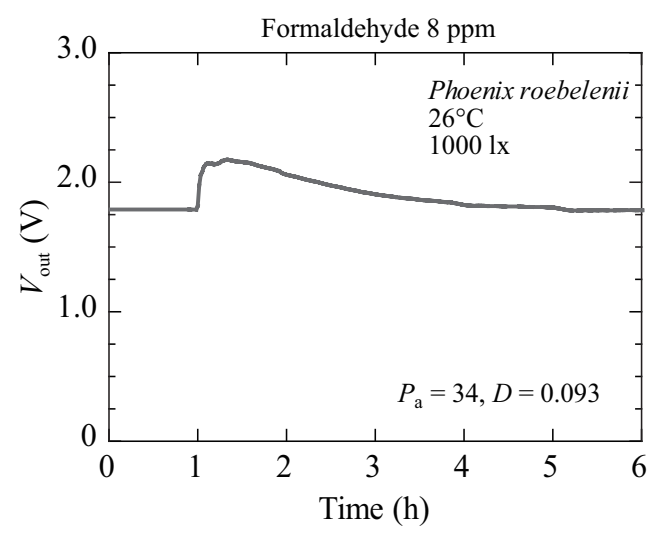

Fig. 4. Purification capability of Roebe for formaldehyde of $8 \mathrm{ppm}$.

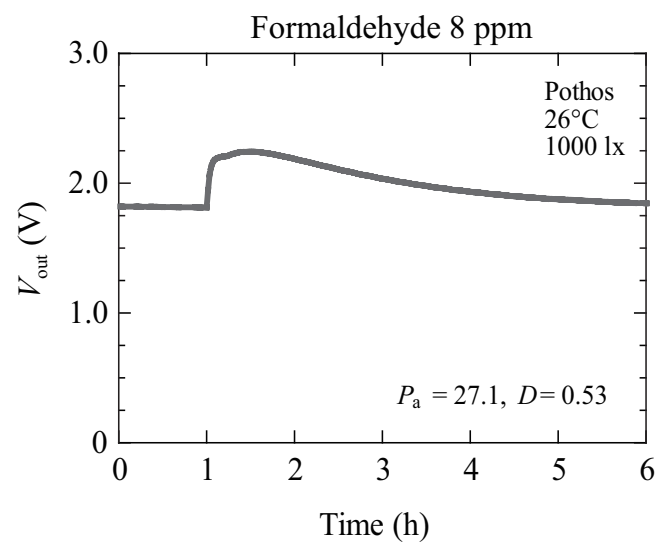

Fig. 5. Purification capability of pothos for formaldehyde of $8 \mathrm{ppm}$.

\subsection{Purification capability dependence on temperature}

Room temperature is usually about 20 to $26^{\circ} \mathrm{C}$ in homes and offices. This temperature range is good for indoor plants. In the homes of elderly people, the optimum temperature is slightly higher. Therefore, the purification capability was examined at temperatures of 21 to $26^{\circ} \mathrm{C}$. The results are shown in Fig. 6. $P_{\mathrm{a}}$ increases as atmospheric temperature increases. The optimum growing temperature of Roebe is 16 to $24^{\circ} \mathrm{C}$. The differential coefficient $D$ is also indicated in the figure. $D$ is defined as follows. Formaldehyde concentration decreases and sensor output also decreases depending on plant purification function after pollutant injection. $D$ is defined as the absolute value of the maximum differential coefficient of the $P_{\mathrm{a}}$ curve. The capability is high when $D$ is large. $P_{\mathrm{a}}$ and $D$ increase as temperature increases and there is a positive correlation between the two. The correlation is shown in Fig. 7. The correlation 


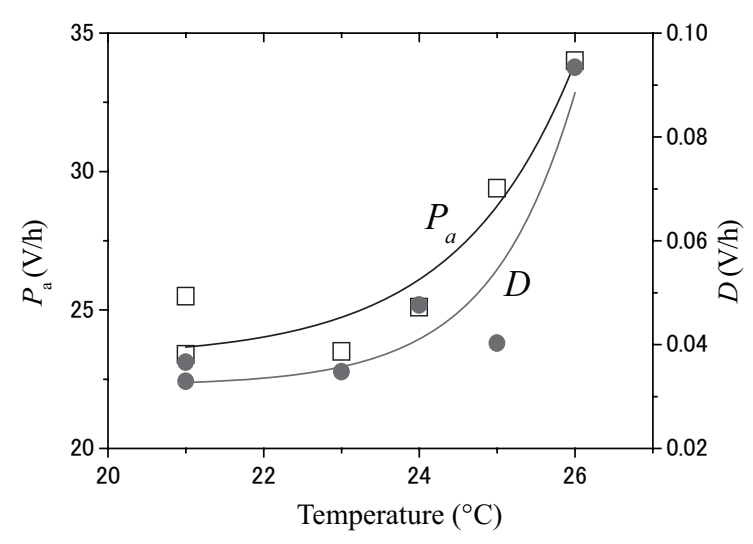

Fig. 6. $\quad P_{\mathrm{a}}$ and maximum differential coefficient $(D)$ of sensor output as a function of atmospheric temperature.

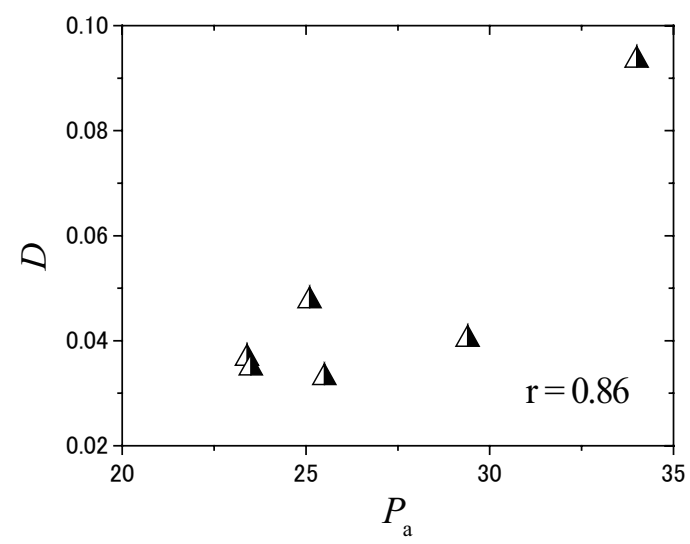

Fig. 7. Correlation between $P_{\mathrm{a}}$ and $D$ for Fig. 6 .

coefficient of the plots is about 0.86 , but it is low at low temperatures. It is thought that the coefficient $D$ denotes a real capability, but common people cannot grasp such a concept. The correlation coefficient means that $P_{\mathrm{a}}$ is also effective for judging the green plant purification capability.

\subsection{Purification function dependence on light intensity}

Illumination is an important environmental factor when humans use a personal computer and carry out clerical work. The intensity is specified by Japanese Industrial Standards (JIS) in each environment, for example, 750-1,500 lx in offices, and 750 $1,000 \mathrm{~lx}$ in computer rooms. The range is aimed at 20 to 40 -year-olds. The optimum light intensity at an office desk is about $750 \mathrm{~lx} . P_{\mathrm{a}}$ was analyzed as a function of light 
intensity. The results are shown in Fig. 8. $P_{\mathrm{a}}$ increases as light intensity increases. It is about 15 at 0 to $500 \mathrm{~lx}$ and exceeds the value of 25 above $700 \mathrm{~lx}$. Roebe has a high capability at the optimum temperature and optimum light intensity in an office environment. The plant indicates photosynthesis at about $350 \mathrm{~lx}$ and emits oxygen above 700 1x. Roebe also has a purification function even at a light intensity below $500 \mathrm{~lx}$. This function is derived from microorganisms living in the potted soil and leaf surfaces. Gaseous pollutants can diffuse into the soil, where they are decomposed by many types of microorganisms.

\subsection{Healing effect of plant}

The term "healing effect" is used frequently nowadays because humans are often tired both mentally and physically. The term is difficult to define and there are many things that exert the healing effect, for example, music, scent, plants, and pets. In this study, the healing effect was evaluated by measuring relief from stress. Alpha amylase is present in saliva as a stress marker. The evaluation was conducted by measuring alpha amylase concentration. Data entry work for a limited time was adopted as the source of stress. The work is an examination (the pre-level 1 Japanese test) for data entry carried out by The Association of Japan Information Processing Examination. The examination time is $10 \mathrm{~min}$. The volume of amylase was analyzed and data for both the presence and absence of Roebe in the examination room were compared. The results are shown in Table 1. $h_{\mathrm{r}}$ decreases in the presence of Roebe. Other values are almost the same

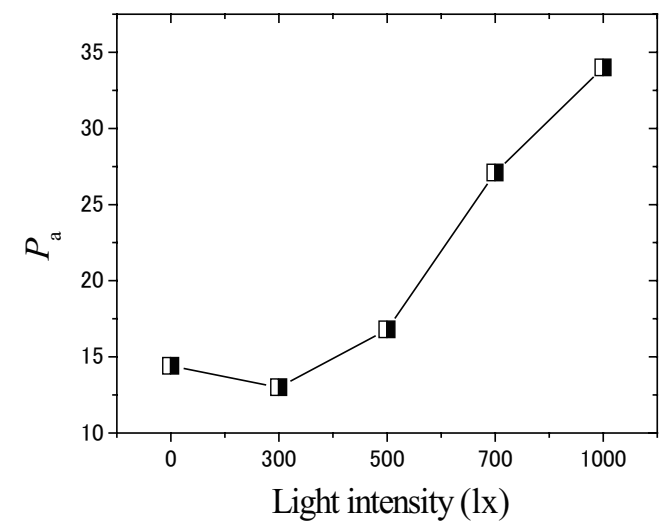

Fig. 8. $\quad P_{\mathrm{a}}$ as a function of atmospheric light intensity.

Table 1

Stress grades determined from amylase activity $(h)$ in the saliva of a subject in environments with and without Roebe.

\begin{tabular}{ccc}
\hline$h$ & without Roebe & with Roebe \\
\hline$h_{\mathrm{b}}$ & 28 & 26 \\
$h_{\mathrm{s}}$ & 62 & 64 \\
$h_{\mathrm{r}}$ & 34 & 24 \\
\hline
\end{tabular}

(unit: kIU/L) 
between the two conditions. It is difficult to measure stress level because it depends on the subject's condition. Only one subject was used, but the measurement was carried out several times. The data were very much the same. However, it is necessary to study many subjects and to perform the measurement several times to obtain more conclusive results. Only one evaluation method is introduced in this investigation. In this method, we expect to evaluate stress using brain waves and other techniques. The results must be compared with each other. It is understood that stress is alleviated during work breaks. Thus, it is necessary to take appropriate breaks to decrease stress in a work environment.

\subsection{Purification capability for styrene}

Roebe is capable of purifying many other airborne chemicals aside from formaldehyde. It takes a long time for this plant to purify large-molecular-weight substances, and in such circumstances, the $P_{\mathrm{a}}$ of Roebe decreases with time. The $P_{\mathrm{a}}$ for styrene was examined for reference in this study. The molecular weight of formaldehyde is 30.03 and that of styrene is 104.15 . The purification capability for styrene is indicated in Fig. 9. Styrene was injected into the chamber at a concentration of $1.5 \mathrm{ppm}$. The $P_{\mathrm{a}}$ of Roebe for styrene was 15.3 in the experiment. The $P_{\mathrm{a}}$ is inversely related to molecular weight and decreases compared with that for formaldehyde. Styrene is mainly emitted by office machines. Toluene and xylene are emitted by building materials.

\subsection{Purification capability for toluene}

Toluene (molecular weight: 92.14) is an organic compound belonging to the aromatic hydrocarbon family. It is a typical airborne chemical contained in coating compounds. Construction companies perform safety assessments by measuring toluene concentration when they construct a building. The concentration of toluene in an indoor environment is required to be below $0.07 \mathrm{ppm}\left(0.26 \mathrm{mg} / \mathrm{m}^{3}\right)$, as specified by the Ministry of Health, Labor and Welfare of Japan. The purification capability of Roebe for toluene is shown in Fig. 10. The concentration of toluene in the chamber was $1.5 \mathrm{ppm}$ at the beginning of the

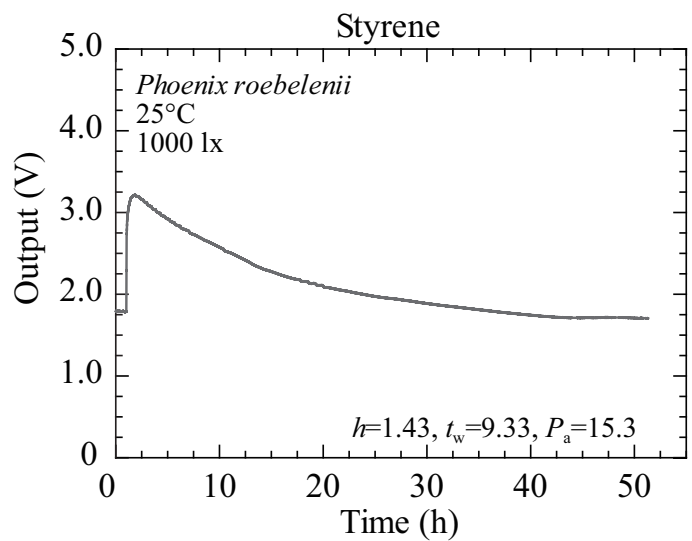

Fig. 9. Purification capability of Roebe for styrene of $1.5 \mathrm{ppm}$. 


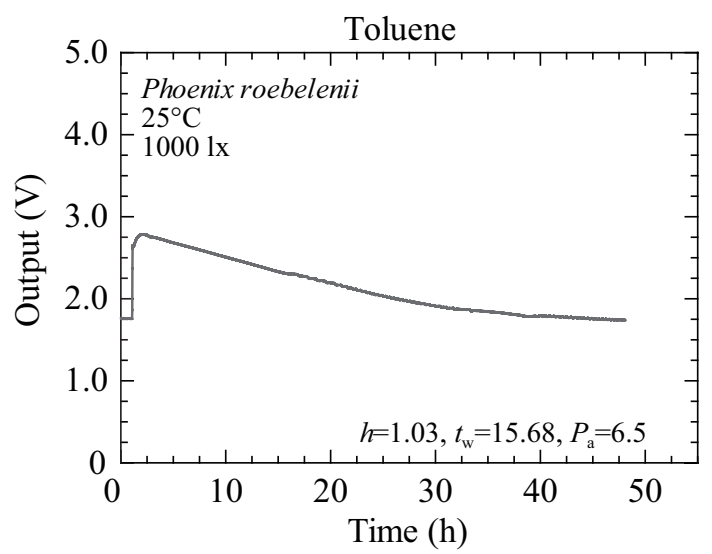

Fig. 10. Purification capability of Roebe for toluene of $1.5 \mathrm{ppm}$.

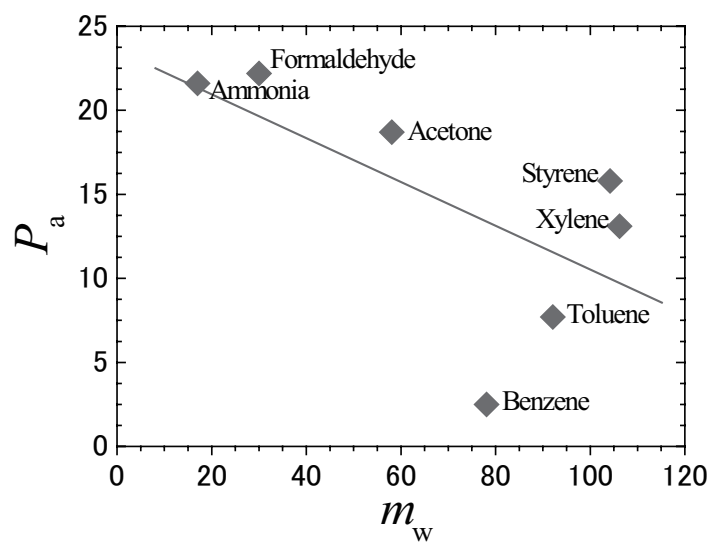

Fig. 11. $P_{\mathrm{a}}$ as a function of molecular weight $\left(m_{\mathrm{w}}\right)$ of polluting chemical.

experiment. $P_{\text {a }}$ was 6.5 , namely, it takes a relatively long time to remove the chemical. Toluene has a lower molecular weight than styrene, and its $P_{\mathrm{a}}$ is low. The relationship between $P_{\mathrm{a}}$ and molecular weight is discussed in the following section. Plants require a long time to purify large-molecular-weight chemicals. Thus, it is better to use smallmolecular-weight and low-risk substances as much as possible.

\subsection{Relationship between purification capability of plant and molecular weight} of pollutant

It is difficult to evaluate a plant's purification capability because plants are living things and their capability depends on environmental factors. However, people want to know the general capability of particular plants to degrade pollutants, and they also 
often desire to live a simple lifestyle designed to reduce the earth's environmental load. The purification capability of Roebe for some chemicals of different molecular weights was investigated in this study. The results are shown in Fig. 11. It took a long time for Roebe to purify and decompose large-molecular-weight chemicals. Thus, it is better to use small-molecular-weight chemicals from the viewpoint of the earth's environmental load.

\section{Conclusions}

The purification capability and healing effect of Roebe, which is endemic to Hachijyo Island, were evaluated. Roebe has a purification capability for airborne chemicals, for example, formaldehyde, toluene, and styrene. It also has a healing effect. However, the effect must be investigated in more detail. An increase in the export volume of Roebe can be achieved by promoting the positive characteristics of this plant obtained in this study. It is also important to control the growth environment of Roebe. Other positive features of the Roebe produced on Hachijyo Island are the slender leaf configuration and reflective leaf surface. These features could be promoted together with the newly found positive characteristics.

\section{Acknowledgment}

Part of this investigation was supported by a Grant-in-aid for Scientific Research (B) (No. 18310062, 2006) from the Ministry of Education, Culture, Sport, Science and Technology of Japan.

\section{References}

1 N. Kasai: Plants Changed Our Earth! (Kagaku-Dojin, Kyoto, 2007).

2 Investigative Committee for Safety and Security Concerning Sensor Technology: Sensor Technology for Safety and Security (Kaibun-Do, Tokyo, 2006).

3 N. Murai: J. Soc. Heating, Air-Conditioning and Sanitary Engineers of Japan 81 (2007) 1.

4 B. C. Wolverton: How to Grow Fresh Air (Penguin Books, New York, 1997).

5 M. Tani, H. Kuroda, A. Sawada and T. Oyabu: J. Soc. Environmental Instrumentation, Control and Automation in Japan 11 (2006) 29.

6 A. Sawada, T. Oyabu, K. Takenaka and T. Yoshida: IEEJ Transactions on Sensors and Micromachines 123-E (2003) 416 (in Japanese).

7 M. Yamaguchi, K. Takeda and M. Murakami: Human Engineering Ergonomics and Welfare Engineering (Corona Co., Tokyo, 2007).

8 Y. Miyazaki: Why is Forest Bathing Good for Health? (Bungeihunju, Tokyo, 2003).

9 M. Yamaguchi and N. Takai: Saliva as a Mirror of the Body (Kogyo Chosakai Publishing, Tokyo, 1999). 